\title{
Maritime Supply Chain Optimization by Using Fuzzy Goal Programming
}

\author{
Bekir Sahin ${ }^{1, *}$, Devran Yazir ${ }^{2}$, Abdelsalam Adam Hamid ${ }^{1}$ and Noorul Shaiful Fitri Abdul Rahman ${ }^{1}$ \\ 1 International Maritime College Oman, Suhar P.C. 111, Oman; abdelsalam@imco.edu.om (A.A.H.); \\ Noorul@imco.edu.om or nsfitri2107@gmail.com (N.S.F.A.R.) \\ 2 Surmene Faculty of Maritime Sciences, Karadeniz Technical University, Trabzon 61080, Turkey; \\ dyazir@ktu.edu.tr \\ * Correspondence: bekir@imco.edu.om; Tel.: +968-94020314
}

Citation: Sahin, B.; Yazir, D.; Hamid, A.A.; Abdul Rahman, N.S.F. Maritime Supply Chain Optimization by Using Fuzzy Goal Programming. Algorithms 2021, 14, 234. https://doi.org/ $10.3390 /$ a14080234

Academic Editor: Frank Werner

Received: 29 June 2021

Accepted: 8 August 2021

Published: 9 August 2021

Publisher's Note: MDPI stays neutral with regard to jurisdictional claims in published maps and institutional affiliations.

Copyright: (C) 2021 by the authors Licensee MDPI, Basel, Switzerland. This article is an open access article distributed under the terms and conditions of the Creative Commons Attribution (CC BY) license (https:// creativecommons.org/licenses/by/ $4.0 /)$

\begin{abstract}
Fuzzy goal programming has important applications in many areas of supply chain, logistics, transportation and shipping business. Business management has complications, and there exist many interactions between the factors of its components. The locomotive of world trade is maritime transport and approximately $90 \%$ of the products in the world are transported by sea. Optimization of maritime operations is a challenge in order to provide technical, operational and financial benefits. Fuzzy goal programming models attract interests of many scholars, therefore the objective of this paper is to investigate the problem of minimization of total cost and minimization of loss or damage of containers returned from destination port. There are various types of fuzzy goal programming problems based on models and solution methods. This paper employs fuzzy goal programming with triangular fuzzy numbers, membership functions, constraints, assumptions as well as the variables and parameters for optimizing the solution of the model problem. The proposed model presents the mathematical algorithm, and reveals the optimal solution according to satisfaction rank from 0 to 1 . Providing a theoretical background, this study offers novel ideas to researchers, decision makers and authorities.
\end{abstract}

Keywords: maritime supply chain; optimization; goal programming; fuzzy sets

\section{Introduction}

The indices published by the international transportation and shipping companies regularly contribute to the maritime supply chains for the shipping companies. According to the Ningbo Containerized Freight Index 2021, the change observed between 2011 and 2021 has a volatility of $8 \%$ continuously. The presence of this volatility and fluctuating price changes reveal the importance of the optimization of maritime supply chains [1].

Nowadays, conditions that increase competition, the high performance of maritime companies in the sectors in which they operate does not only depend on their own success performances. The success of other parameters of maritime businesses directly affects the success of these businesses. For this reason, maritime businesses should pay attention to the supply chain and use the supply chain effectively. Hub-ports are economically important centers where cargoes from land or feed ports to destination ports are transferred [2,3]. Special cargoes which produced in the market are stored in hub-ports for a certain period. Then, some systematic operations related to these cargoes are organized in hub-ports such as containerization, storage, transportation, classification, etc. It is handled by the operations, and delivered to destination ports and distributors. To achieve success in increasing competitive conditions, the cargoes must be delivered to the end-user in desired amounts, systematically, regularly, and without damage or with a little damage. These might be the main indicators for the success of supply chain. Therefore, each part of the supply chain must work both on its own and in cooperation with other parts in the chain. In addition, beyond a technical activity, supply chain management adopts 
maritime businesses based on management philosophy to maximize the benefits that will be obtained $[4,5]$.

Supply chain management enables maritime businesses to compete by taking advantage of more comprehensive, planned, and organized opportunities in the transportation sector. Besides, with the supply chain management, the costs can be minimized by fulfilling the requests of the end-users in a shorter time. It is the parameters that should be in a competitive environment to transport the desired cargo to the destination ports at the desired number, on time and with the least cost. To minimize the cost of road, railway, and sea transportation and to maximize customer satisfaction, optimization of supply chain management must be created and implemented effectively. Ultimately, effective supply chain management will lead to reduced inventories and waiting times, lower operational costs, and delivery of cargo to the ports at the appropriate time. In this case, the creation and optimization of the maritime supply chain become more important [6].

Shipping companies should choose the best price for transportation prices of the cargo where carried in the maritime supply chain in a competitive environment. They are also required to carry out studies to minimize storage and operation processes. Maritime supply chain structures, which include many transportation and logistics companies aim to provide fast, cooperative, synchronized, minimum cost, and customer satisfaction from the first point of cargo to the endpoint. The main objectives of an effective supply chain management are to store low-cost and quality products in hub-ports and deliver them to customers as quickly as possible [7].

Maritime transport has played an important role in facilitating international trade in many globalized industries, as there is often a tendency to maritime services in supply chain management. This process has reshaped the roles and strategies of hub-ports and port users used for the global supply chain [8].

In general, there are two broad strategies that can be adopted to structure the resources, capabilities or activities of maritime shipping companies and to compete in the maritime transport industry. These are low cost and differentiation strategies. While both strategies are important and need to be followed simultaneously by one firm, one must have a higher priority strategy than the other. The reason for this is that their activities that support both strategies are somewhat contradictory, and often trade is necessary for a firm to gain a sustainable competitive position in the market [9-11]. A shipping company that follows a low-cost strategy competes on price, i.e., freight rate or other equivalents. In this case, it competes by obtaining economies of scale in operations, centralizing facilities and functions, adopting strict financial accounting, and minimizing service features [12].

Leading maritime companies in the supply chain should move away from classical approaches. Considering supply chain management in one piece, it should reduce total costs and explore ways to increase competition by adding more values. The real competition is not between maritime transport companies but among the supply chains [13].

Supply chain management can be defined as a process that maritime companies carry out and plan to achieve mutual benefits and goals in transportation operations. To mention several advantages of supply chain management, integrating the supply chain to maritime companies leads to reduced transport and transaction costs, improved access to new markets and improved service quality. However, little attention has been paid to the integration of supply chain management in the maritime industry [14].

There are uncertainties in supply chain parameters from different viewpoints such as quality, quantity, delivery time. These uncertainties can be evaluated in three different groups such as demand, process, and supply $[15,16]$.

Uncertainty in supply is the uncertainty caused by delays or errors in deliveries [17]. In short, delay in delivery time may result from errors such as quantity errors in delivery or product damage. The uncertainty in the process is due to the low reliability of the production process. Finally, the uncertainty in demand is the most important one. In other words, volatility in demand and uncertainty caused by erroneous demand forecasts [18]. 
The demands of the end user can be stated in some linguistic expressions. These linguistic and verbal variables can be expressed at certain intervals. For example, when expressing the request, the following statements can be used: It may be less than a specific request for $t_{1}$, or $t_{2}$ may be more, or it may be approximately equal to the demand for $t_{3}$. These statements can be shown with membership functions in fuzzy logic.

Uncertainty is the most important factor affecting activity and coordination in the supply chain management decision process as well as affecting the operating performance of the system [19]. In many studies, uncertainties in the supply chain have been modeled by probability distributions. Probability distributions are generally obtained by examining the situations recorded in the past [20]. However, when statistical data are unreliable or incomplete, stochastic models may not be a good choice [21]. In this case, imprecise parameters can be determined based on experience and subjective managerial judgment [22] Generally, the relevant expert can say the value range for a parameter and make an estimate of what value this parameter will most likely receive in that range. The fuzzy set theory, which requires simpler and less data than the probability theory used for the uncertainties in the supply chain, maybe an alternative approach $[23,24]$. Fuzzy set theory is used to model systems that are difficult to define precisely $[25,26]$. Fuzzy set theory is introduced as a method that adds variability and subjectivity to solution processes [27,28]. It is seen that fuzzy modeling is also common in the field of supply chain modeling $[29,30]$.

In this study, a network optimization model is created mathematically for any maritime supply chain problem operating under uncertain demand conditions. Fuzzy goal programming is implemented. A problem has been created that minimizes container shipping costs and damage to cargoes throughout special cargo. This model was analyzed, the results were examined, and its appropriateness was evaluated.

In Section 2, fuzzy goal programming is given. Section 3 provides the proposed model of maritime supply chain. Section 4 discusses the results and current status of maritime industry. Finally, the last section concludes the paper.

\section{Fuzzy Goal Programming}

Goals and constraints are determined clearly in the goal programming formulation. According to [31], it is mostly hard for the decision makers to determine the access level for each objective functions. Access levels are determined based on preference priorities and relative weights of the goals and subjective evaluations of decision makers. Fuzzy logic is used as linguistic variables for the subjectivity in goal programming [32]. The decision makers might not always provide the exact values of the goals. Therefore, linguistic variables help decision makers to make an appropriate evaluations. For instance, a decision maker might evaluate the goals by some comparisons such as "lower than $g_{1}$ ", "higher than $g_{2}$ ", etc. Membership function of a fuzzy number represents the satisfaction level of the goals. If the membership function is equal to 1 , it means that the goals are fully satisfied, if it is 0 , the goal is not reached. If it is between 0 and 1 , the goal is achieved partially. The fuzzy logic can also be employed to the parameter values and right hand side constants of constraints. The $=, \leq, \geq$ signs provide tolerance [33]. A fuzzy constraint can be shown as $\tilde{C}$ fuzzy set or $\mu_{\tilde{C}}(x) \in[0,1]$ which is a subset of universe set where $\mu_{\tilde{C}}(x)=1$, $0<\mu_{\tilde{C}}(x)<1$ and $\mu_{\tilde{C}}(x)=0$ represent fully satisfied, partially satisfied and not satisfied respectively. The general structure of goal programming is given below $[34,35]$ :

$$
\begin{array}{rr}
x_{i} & i=1,2 \ldots n \\
A_{j}\left(x_{i}\right) \prec \overline{\mathrm{A}_{\mathrm{j}}} & j=1,2, \ldots J \\
A_{k}\left(x_{i}\right) \succ \overline{\mathrm{A}_{\mathrm{k}}} & k=m+1, m+2, \ldots K \\
f_{l}(x) \leq b_{l} & l=1,2, \ldots L \\
x_{i} \geq 0 & i=1,2 \ldots n
\end{array}
$$


where $A_{j}\left(x_{i}\right)$ is the $j$ th objective function, $\overline{\mathrm{A}_{\mathrm{j}}}$ is the target value for the $j$ th goal. $A_{k}\left(x_{i}\right)$ is the $k$ th constraint, $\overline{\mathrm{A}_{\mathrm{k}}}$ is the target value for the $k$ th goal. $f_{l}(x)$ is the inequality constraint, $b_{l}$ is the amount of probable or reachable source.

In the literature, there exist several goal programming models [36,37]. Ref. [38] formulates the goal programming as follows:

$$
\begin{array}{lll}
\max & \lambda(x)=\gamma \lambda_{0}+(1+\gamma) \sum_{k} \theta_{k} \mu_{A_{k}}(x) & \\
\text { s.t. } & \lambda_{0} \leq \mu_{A_{k}}(x) & \\
& x \in f(x) & \\
& \lambda_{0}, \gamma \in[0,1]
\end{array}
$$

where $\mu_{A_{k}}(x)$ is the satisfaction level of $k$ th objective function. $\lambda_{0}$ is the minimum satisfaction level of goals. $\theta_{k}$ is a parameter that shows the relative importance value where $\sum_{k} \theta_{k}=1$ and $\theta_{k}>0 . \gamma$ is a compensation coefficient checks for the compromises from the target. If the $\gamma$ is set higher, it means that $\lambda_{0}$ is desired to be higher [39].

\section{Proposed Model}

\subsection{Definition and Formulation of Problem}

In this study, the optimization of the maritime supply chain for containerized special cargoes is studied as a theoretical perspective. Three different special cargoes coming from three different (feeder ports) suppliers to the hub-port, are shipped to the five different destination ports for six months. These cargoes are primarily stored in certain warehouses of the hub-port. These cargoes are then containerized in a standard form. This standard form is predetermined in line with the needs of the destination ports. Fuzzy goal programming model is set for the solution of this problem. A model is established to minimize the returns of customers with the total cost of maritime supply chain and container losses and losses in the network. Demands and objective functions are set as fuzzy numbers.

\subsection{Assumptions}

1. There always has a deterministic dynamic demand at destination ports.

2. Objective functions and demands in destination ports are fuzzy.

3. All objective functions and constraints are linear.

4. Triangular fuzzy numbers are preferred for the fuzzy demand of the destination ports.

5. Linear membership functions are used to represent the objective goals.

6. The feeder ports are known.

7. Each feeder port has the capacity to meet the awaited cargo.

8. Hub-port operations are conducted in a single stage.

9. Operation capacity of hub-port is known.

10. Hub-port always provides storage cargo handling and transportation for all cargoes.

11. Unit stocking fees of the cargoes are fixed.

12. There is no cargo at the beginning of the first period.

13. Cargo handling cost is constant.

14. Arrival regime of cargoes varies by month.

As given in Figure 1, this is a transshipment process under several parameters and decision variables. All possibilities have been taken into account as much as possible for the feeder port, hub-port and destination ports. The parameters deal with the demand, operation capacity, amount of cargo, situations of storage area, cost, safety stock and loss or damage of containers. There are six decision variables and the model tracks the changes at these decision variables. There are two goals, minimization of total cost and minimization of loss or damage of containers returned from the destination port. 


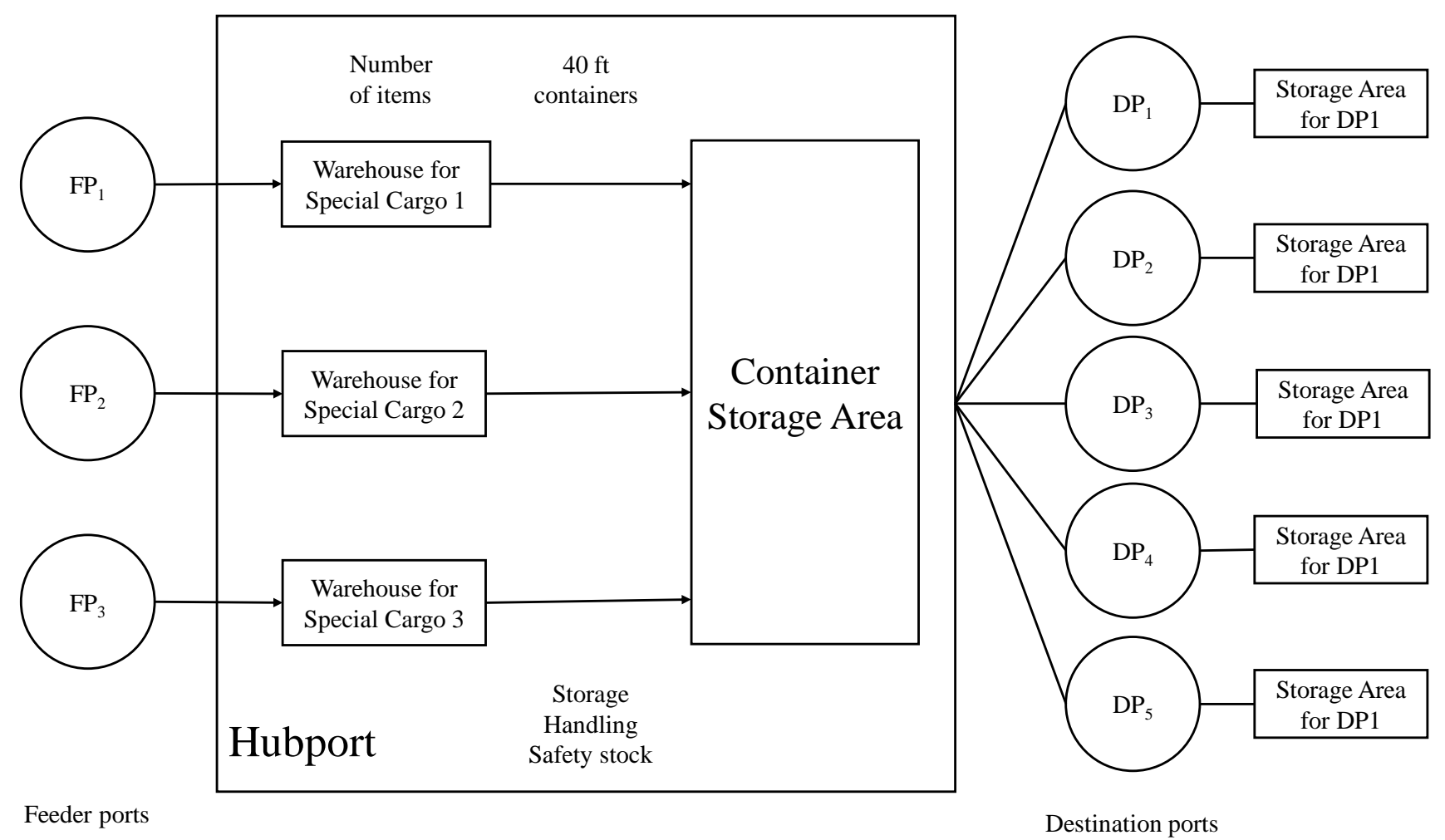

Figure 1. Structure of the proposed model for maritime supply chain.

\section{Indices:}

$t$ : Time ( $\mathrm{t}$ in months)

$s:$ Special cargo type (s)

$d$ : Destination ports $(\mathrm{d})$

\section{Parameters:}

$M_{d t}$ : Fuzzy demand (M) of the destination ports (d) at time $t$

$o$ : Operation capacity (o) of hub-port

$a_{s}$ : The amount of special cargoes (s) for a 40FT standard container

$S A_{S}$ : Storage area (SA) for each special cargo (s) at the hub-port

$S A_{k}$ : Storage area (SA) for containers $(\mathrm{k})$ at the hub-port

$S A_{d}$ : Storage area (SA) of destination ports (d)

$T_{S}$ : Transportation cost $(\mathrm{T})$ of special cargo (s)

co: Cost (c) of unit operation (o)

$T_{d t}$ : Transportation cost $(\mathrm{T})$ of unit container to the destination port $(\mathrm{d})$ at time $t$

$S c_{s}$ : Unit storage cost $(\mathrm{Sc})$ of special cargo (s) at hub-port

$S c_{k}$ : Unit storage cost $(\mathrm{Sc})$ for a container $(\mathrm{k})$ at hub-port

$S c_{d}$ : Storage cost (Sc) of a container at destination port (d)

$f_{s}$ : Amount of safety stock (f) for special cargoes (s) at hub-port

$f_{k}$ : Amount of safety stock (f) for containers (k) at hub-port

$f_{d}$ : Amount of safety stock (f) at destination port (d)

$l_{d}$ : loss or damage (l) of containers returned from destination port (d)

\section{Decision Variables:}

$I_{s t}$ : The amount of special cargo (s) transported from the feeder ports at the time $t$

$K_{t}$ : The amount of containerized cargo at time $t$

$L_{d t}$ : The number of transported containers to the destination ports $(\mathrm{d})$ at the time $(\mathrm{t})$

$R_{s t}$ : The amount of special cargo (s) at hub-port at the end of time $t$

$R_{t}$ : The amount of containers at hub-port at the end of time $t$ 
$R_{d t}$ : The amount of containers at destination port (d) at the end of time $t$

Two goals are set for maritime supply chain optimization

1. Minimization of total cost

2. Minimization of loss or damage of containers returned from destination port

$$
\begin{aligned}
\text { Min Total Cost }(\mathrm{TC})= & \text { Total Supply Cost (TSC) }+ \text { Total Operation Cost (TOC) } \\
& + \text { Total Distribution Cost (TDC) }
\end{aligned}
$$

Total Returned Containers (TRC)=loss or damage of containers returned from destination port

$$
\begin{gathered}
\mathrm{TSC} \cong \sum_{t=1}^{T} \sum_{s=1}^{S} T_{S} \cdot I_{s t}+\sum_{t=1}^{T} \sum_{s=1}^{S} S c_{s} \cdot R_{s t} \\
\mathrm{TOC} \cong \sum_{t=1}^{T}\left(c o \cdot K_{t}+S c k \cdot R_{t}\right) \\
\mathrm{TDC} \cong \sum_{t=1}^{T} \sum_{d=1}^{D} T_{d t} \cdot L_{d t}+\sum_{t=1}^{T} \sum_{s=1}^{S} S c_{d} \cdot R_{d t} \\
\mathrm{TC}=\mathrm{TSC}+\mathrm{TOC}+\mathrm{TDC} \\
\mathrm{TRC} \cong \sum_{t=1}^{T} \sum_{d=1}^{D} L_{d t} \cdot l_{d}
\end{gathered}
$$

$$
\begin{array}{rlr}
\min & T C \\
\min & T R C \\
\text { s.t. } & R_{s, t-1}+I_{s t}-R_{s t} \geq a_{s} \cdot K_{t} & \forall s, t \\
& R_{t-1}+K_{t}-R_{t} \geq \sum_{d=1}^{D} L_{d t} & \forall d, t \\
& R_{d, t-1}+L_{d t}-R_{d t} \geq M_{d t} & \forall d, t \\
& R_{d t} \geq f_{d} & \forall d, t \\
& R_{s t} \geq f_{s} & \forall s, t \\
& R_{t} \geq f_{k} & \forall t \\
& K_{t} \leq o & \forall t \\
& L_{d t} \geq M_{d t} & \forall d, t \\
& R_{s t} \leq S A_{s} & \forall s, t \\
& R_{t} \leq S A k & \forall t \\
& R_{d t} \leq S A_{d} & \forall d, t \\
& I_{s t}, K_{t}, L_{d t}, R_{s t}, R_{t}, R_{d t} \geq 0 & \forall d, s, t
\end{array}
$$

\subsection{Definition of Membership Functions}

In this study, linear membership functions are preferred based on fuzzy goal and fuzzy constraints solution methodology. General structure of membership function is illustrated as follows:

$$
\mu_{h}(x)= \begin{cases}Y_{i}(x)<g_{i} & \Rightarrow 1 \\ g_{i}<Y_{i}(x)<g_{i}+h_{i} & \Rightarrow \frac{\left(g_{i}+h_{i}\right)-Y_{i}(x)}{h_{i}} \\ Y_{i}(x)>g_{i}+h_{i} & \Rightarrow 0\end{cases}
$$


where $Y_{i}(x)$ is an objective function, and $g_{i}$ and $h_{i}$ are the lower bound and the tolerance level, respectively (Figure 2).

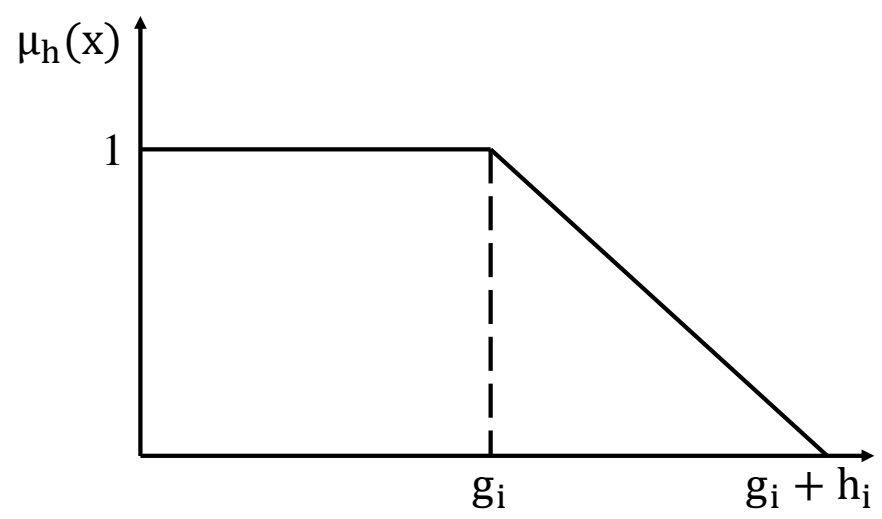

Figure 2. Linear membership function for $i$ th goal.

In the structured model, triangular fuzzy numbers are used that represent the vague demand quantities. In the Figure 3, triangular fuzzy demand is shown as $\tilde{M}_{d t}=\left(\tilde{M}_{d t}^{p}, \tilde{M}_{d t}^{m}, \tilde{M}_{d t}^{o}\right)$. where $\tilde{M}_{d t}^{p}, \tilde{M}_{d t}^{m}$ and $\tilde{M}_{d t}^{o}$ show the possible pessimistic, probable and optimistic values of demand.

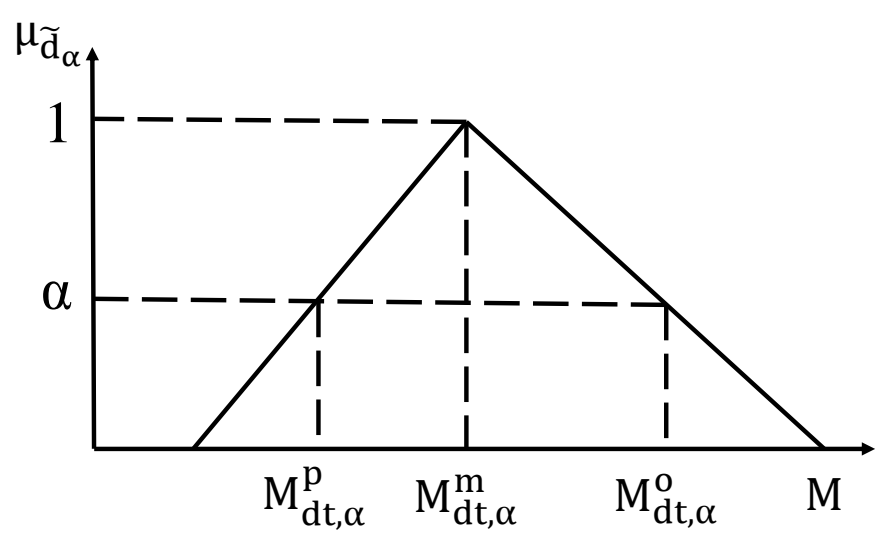

Figure 3. Fuzzy triangular demand.

Weighted average method is preferred for the defuzzification of fuzzy demand. According to tolarable minimum membership function $\alpha$ (alpha), fuzzy constraint is designed as non-fuzzy constraints as shown in Equations (10) and (11). (Lai, Hwang, 1992; Torabi, Hassini, 2008, 2009; Liang, 2006, 2008, 2011).

$$
\begin{gathered}
R_{d, t-1}+L_{d t}-R_{d t} \geq w_{1} \cdot \tilde{M}_{d t, \alpha}^{p}+w_{2} \cdot \tilde{M}_{d t, \alpha}^{m}+w_{3} \cdot \tilde{M}_{d t, \alpha}^{o} \\
L_{d t} \geq w_{1} \cdot \tilde{M}_{d t, \alpha}^{p}+w_{2} \cdot \tilde{M}_{d t, \alpha}^{m}+w_{3} \cdot \tilde{M}_{d t, \alpha}^{o}
\end{gathered}
$$

Here, $w_{1}, w_{2}, w_{3}$ represent the pessimistic, probable and optimistic values that shows the decision maker's priorities.

$$
w_{1}+w_{2}+w_{3}=1 \text { where } 0 \leq w_{1}, w_{2}, w_{3} \leq 1
$$




\subsection{Equivalent Linear Programming Model}

As follow:

$$
\begin{array}{rlrl}
\max \lambda(x)= & \gamma \lambda_{0}+(1+\gamma)\left[\theta_{1} \frac{\left(g_{1}+h_{1}\right)-T C}{h_{1}}+\theta_{2} \frac{\left(g_{2}+h_{2}\right)-T R C}{h_{2}}\right] & \\
\text { s.t. } & \lambda_{0} \leq \frac{\left(g_{1}+h_{1}\right)-T C}{h_{1}} & \\
& \lambda_{0} \leq \frac{\left(g_{2}+h_{2}\right)-T R C}{h_{2}} & \\
& R_{d, t-1}+L_{d t}-R_{d t} \geq w_{1} \cdot \tilde{M}_{d t, \alpha}^{p}+w_{2} \cdot \tilde{M}_{d t, \alpha}^{m}+w_{3} \cdot \tilde{M}_{d t, \alpha}^{o} & & \forall m, t \\
& L_{d t} \geq w_{1} \cdot \tilde{M}_{d t, \alpha}^{p}+w_{2} \cdot \tilde{M}_{d t, \alpha}^{m}+w_{3} \cdot \tilde{M}_{d t, \alpha}^{o} & \forall m, t \\
& R_{s, t-1}+I_{s t}-R_{s t} \geq a_{s} \cdot K_{t} & \forall s, t \\
& R_{t-1}+K_{t}-R_{t} \geq \sum_{d=1}^{D} L_{d t} & & \forall d, t \\
& R_{d t} \geq f_{d} & & \forall d, t \\
& R_{s t} \geq f_{s} & \forall s, t \\
& R_{t} \geq f_{k} & \forall t \\
& K_{t} \leq o & \forall t \\
& R_{s t} \leq S A_{s} & \forall s, t \\
& R_{t} \leq S A_{k} & \forall t \\
& R_{d t} \leq S A_{d} & \forall d, t \\
& \lambda_{0} \gamma \in[0,1] & \\
& I_{s t}, K_{t}, L_{d t}, R_{s t}, R_{t}, R_{d t} \geq 0 & \forall d, s, t
\end{array}
$$

\section{Discussion}

From the start of international trading, transportation by sea represented the primary method for international trading and exchange of goods. And as the industries grew throughout time, Maritime Supply Chain (MSC) became more embedded in the operations of almost all businesses and industries. MSC definition and description are seemingly unclear, and its categorization from the supply chain discipline is not fully conceived. Hence, it represents a great area for research and review. As an attempt to define the term MSC, several researchers disassembled the sub-terms that form MSC, i.e., Maritime carriage and Supply Chain management, and defined them separately [40,41]. Maritime carriage is the transport of items or commuters from one port to another by sea. While supply chain was defined by The Council of Supply Chain Management Professionals (CSCMP), 2016 as follows; "supply chain management encompasses the planning and management of all activities involved in sourcing and procurement, conversion and all logistics management activities. Importantly it also includes co-ordination and collaboration with channel partners, which can be suppliers, intermediaries, third-party service providers, and customers". Nowadays, maritime carriage is merged to the field of supply chain management, and its governance nature is always conceived from a logistical point of view [42]. Optimization is making the most out of something, and in several fields, it is utilized to solve problems and attain goals. After defining a model that describes the issue to be optimized, the optimization process should deliver that model to the specified goal, e.g., minimum, maximum or specific goals. Figure 4 shows the categorization of optimization methods. 


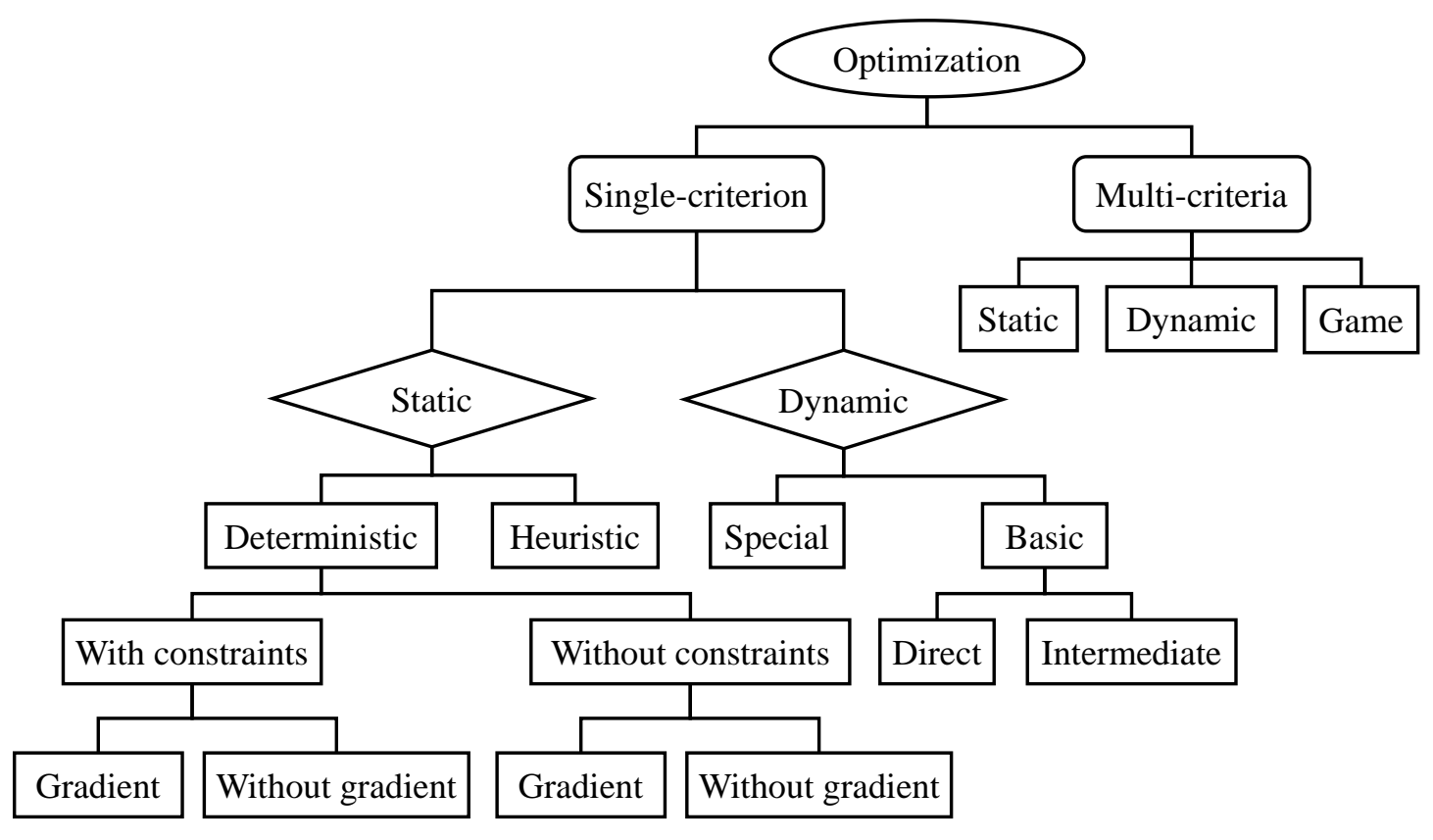

Figure 4. Categorization of optimization methods [43].

The MSC operation involves numerous activities and processes that require careful planning and monitoring. And optimization in logistical practices and processes is necessary to solve problems, reduce costs, improve services, and keeping a competitive stance in the market. Optimizing processes, costs or any logistical element in MSC, usually aims for economic and efficiency criteria, hence the need for multi-criteria optimization methods rather than single-criteria methods [43]. The Institute of logistics Information Technology (LIT) summarized the research areas of MSC and it is shown in Figure 5 [44]. The MSC areas for optimization can be categorized into two main segments, i.e., container port operation and design.

1. The operation segment optimizes the interaction between the ports on one hand and the shippers, manufacturers and transport companies i.e., Trucks and railways, on the other hand. This interaction is comprised of the moving elements in inland transports, namely; trucks, chassis and containers.

2. The design segment focuses on optimizing the vessel operation at sea. It deals with the intercontinental container transport and the interaction between different ports. This segment correlates to the review criteria of this work.

This work aims at systematically tracking literature in optimization practices in MSC, specifically the practices that relate to operations between ports rather than inland operations. Using Google Scholar search engine, the findings of the preliminary search of literature were conducted in the following manner:

1. Realizing the number of articles concerning MSC by searching articles' titles with the following keywords: "Maritime", "Logistics" and "Supply chain". The number of articles equaled 688.

2. Realizing the number of articles concerning optimization research in MSC by adding the keyword "Optimization" in the search engine, without the condition of it being in the title of the article. The number of articles equaled 202.

3. Realizing the number of articles to be included in the review with a quick read of title and abstract, to see if the articles fit the review criteria i.e., optimization in MSC.

4. Realizing the number of articles to be included via a thorough read of the articles that fit the review criteria to include the ones that match the eligibility criteria i.e., optimization of operations between ports in MSC. 


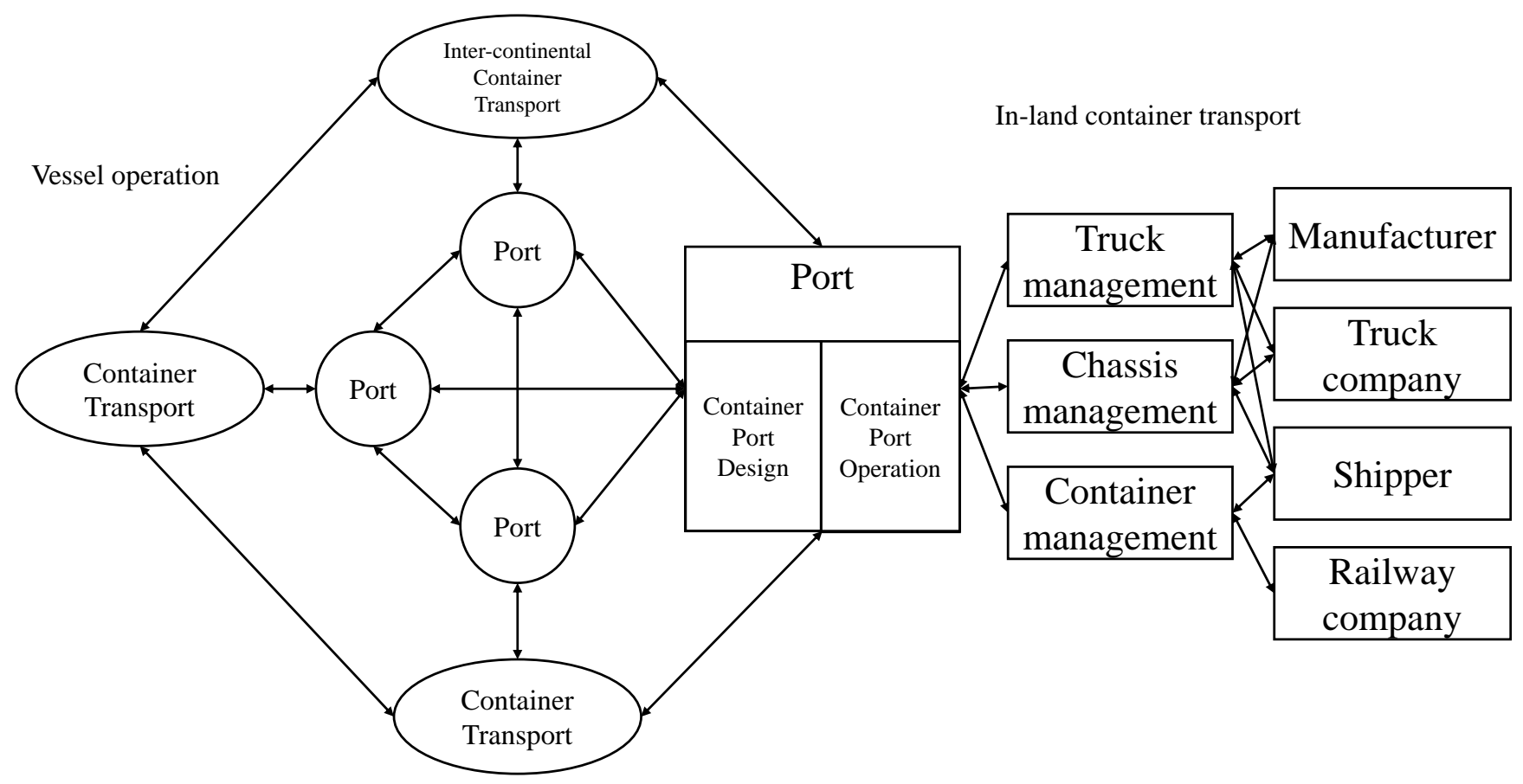

Figure 5. Summary of research in MSC [43].

\section{Conclusions}

International transshipment is the today's reality and should be considered as an important milestone for the conventional means of transport. Transshipment might involve in several processes such as consolidation, de-consolidation, customs controls, etc. Therefore, optimization of transshipment process is significant in terms of finance, time and safety.

This paper aims to solve maritime supply chain problem operating under uncertain demand conditions. Two goals are targeted as minimization of total cost and minimization of loss or damage of containers returned from destination port, and problem is analyzed by using fuzzy goal programming. First, we define and formulate the problem, then assumptions and constraints are identified. The algorithm for fuzzy goal programming is introduced along with fuzzy decision variables and fuzzy parameters.

The model is established to minimize the returns of customers with the total cost of maritime supply chain and container losses and losses in the network. Linear membership functions are used to represent the objective goals in addition Weighted average method for the defuzzification of fuzzy demand. A fuzzy constraint can be shown as $\tilde{C}$ fuzzy set or $\mu_{\tilde{C}}(x) \in[0,1]$ which is a subset of universe set where $\mu_{\tilde{C}}(x)=1,0<\mu_{\tilde{C}}(x)<1$ and $\mu_{\tilde{C}}(x)=0$ represent fully satisfied, partially satisfied and not satisfied respectively.

In the future, scenario-based stochastic models will be considered for maritime supply chain optimization models. Since this is one of our early efforts for maritime supply chain optimization, more complex problems, cases, models and scenarios will be developed for the future research.

Finally, the proposed model can enable decision makers to decide on both situation possible pessimistic, probable and optimistic values of demand and the decisions priorities, decision maker can also decide on the minimum level of losses or damages.

Author Contributions: Conceptualization, B.S.; Methodology, B.S.; Writing-original draft, B.S.; Writing-review \& editing, D.Y., A.A.H. and N.S.F.A.R. All authors have read and agreed to the published version of the manuscript.

Funding: This research received no external funding. 
Institutional Review Board Statement: Not applicable.

Informed Consent Statement: Not applicable.

Data Availability Statement: Not applicable.

Acknowledgments: We would like to express our special thanks to Editor and the anonymous reviewers for careful reading of the paper, and for providing valuable comments and suggestions which have helped improve both the content and the presentation.

Conflicts of Interest: The authors declare no conflict of interest.

\section{References}

1. Index, N.C.F. Ningbo Containerised Freight Index. Available online: https://www.balticexchange.com/market-information/ containers/ningbo/ (accessed on 10 June 2020).

2. Wang, Y.; Yeo, G.T. Transshipment hub port selection for shipping carriers in a dual hub-port system. Marit. Policy Manag. 2019, 46, 701-714. [CrossRef]

3. Duru, O.; Shibasaki, R.; Segi, S. Maritime transport in regional context, governance and environmental phenomenon. Marit. Policy Manag. 2019, 46, 1-3. [CrossRef]

4. Chen, K.; Xu, S.; Haralambides, H. Determining hub port locations and feeder network designs: The case of China-West Africa trade. Transp. Policy 2020, 86, 9-22. [CrossRef]

5. Wan, C.; Yan, X.; Zhang, D.; Qu, Z.; Yang, Z. An advanced fuzzy Bayesian-based FMEA approach for assessing maritime supply chain risks. Transp. Res. Part Logist. Transp. Rev. 2019, 125, 222-240. [CrossRef]

6. Lakhal, S.Y. A Study on the Maritime Transport Network Design under Different Charter Rates: The Case of LNG Transport between Qatar \& Turkey. Oper. Supply Chain. Manag. 2018, 11, 13-25.

7. Azevedo, S.G.; Pimentel, C.M.; Alves, A.C.; Matias, J.C. Support of Advanced Technologies in Supply Chain Processes and Sustainability Impact. Appl. Sci. 2021, 11, 3026. [CrossRef]

8. Seo, Y.J.; Dinwoodie, J.; Roe, M. The influence of supply chain collaboration on collaborative advantage and port performance in maritime logistics. Int. J. Logist. Res. Appl. 2016, 19, 562-582. [CrossRef]

9. Gallego-García, S.; García-García, M. Market-Oriented Procurement Planning Leading to a Higher Service Level and Cost Optimization. Appl. Sci. 2020, 10, 8734. [CrossRef]

10. Senol, Y.E.; Sahin, B. A novel real-time continuous fuzzy fault tree analysis (RC-FFTA) model for dynamic environment. Ocean. Eng. 2016, 127, 70-81. [CrossRef]

11. Lagarda-Leyva, E.A.; Bueno-Solano, A.; Vea-Valdez, H.P.; Machado, D.O. Dynamic Model and Graphical User Interface: A Solution for the Distribution Process of Regional Products. Appl. Sci. 2020, 10, 4481. [CrossRef]

12. Yuen, K.F.; Thai, V.V.; Wong, Y.D. Corporate social responsibility and classical competitive strategies of maritime transport firms: A contingency-fit perspective. Transp. Res. Part Policy Pract. 2017, 98, 1-13. [CrossRef]

13. Hossain, N.U.I.; El Amrani, S.; Jaradat, R.; Marufuzzaman, M.; Buchanan, R.; Rinaudo, C.; Hamilton, M. Modeling and assessing interdependencies between critical infrastructures using Bayesian network: A case study of inland waterway port and surrounding supply chain network. Reliab. Eng. Syst. Saf. 2020, 198, 106898. [CrossRef]

14. Yuen, K.F.; Thai, V. Barriers to supply chain integration in the maritime logistics industry. Marit. Econ. Logist. 2017, 19, 551-572. [CrossRef]

15. Peidro, D.; Vasant, P. Transportation planning with modified S-curve membership functions using an interactive fuzzy multiobjective approach. Appl. Soft Comput. 2011, 11, 2656-2663. [CrossRef]

16. Kabak, Ö.; Ülengin, F. Possibilistic linear-programming approach for supply chain networking decisions. Eur. J. Oper. Res. 2011, 209, 253-264. [CrossRef]

17. Alogla, A.A.; Baumers, M.; Tuck, C.; Elmadih, W. The Impact of Additive Manufacturing on the Flexibility of a Manufacturing Supply Chain. Appl. Sci. 2021, 11,3707. [CrossRef]

18. UNCTAD. Review of Maritime Transport; United Nations Conference on Trade and Development: New York, NY, USA; Geneva, Switzerland, 2017.

19. Sahin, B.; Yip, T.L. Shipping technology selection for dynamic capability based on improved Gaussian fuzzy AHP model. Ocean Eng. 2017, 136, 233-242. [CrossRef]

20. Petrovic, D.; Roy, R.; Petrovic, R. Supply chain modelling using fuzzy sets. Int. J. Prod. Econ. 1999, 59, 443-453. [CrossRef]

21. Wang, J.; Shu, Y.F. Fuzzy decision modeling for supply chain management. Fuzzy Sets Syst. 2005, 150, 107-127. [CrossRef]

22. Şahin, B.; Yazır, D. An analysis for the effects of different approaches used to determine expertise coefficients on improved fuzzy analytical hierarchy process method. J. Fac. Eng. Archit. Gazi Univ. 2019, 34, 89-102.

23. Dubois, D.; Fargier, H.; Fortemps, P. Fuzzy scheduling: Modelling flexible constraints vs. coping with incomplete knowledge. Eur. J. Oper. Res. 2003, 147, 231-252. [CrossRef]

24. Şahin, B. Route prioritization by using fuzzy analytic hierarchy process extended dijkstra algorithm. J. ETA Marit. Sci. 2019, 7, 3-15. [CrossRef] 
25. Sahin, B.; Yazidi, A.; Roman, D.; Soylu, A. Ontology-Based Fault Tree Analysis Algorithms in a Fuzzy Environment for Autonomous Ships. IEEE Access 2021, 9, 40915-40932. [CrossRef]

26. Sahin, B.; Soylu, A. Intuitionistic fuzzy analytical network process models for maritime supply chain. Appl. Soft Comput. 2020, 96, 106614. [CrossRef]

27. Sahin, B.; Soylu, A. Multi-layer, multi-segment iterative optimization for maritime supply chain operations in a dynamic fuzzy environment. IEEE Access 2020, 8, 144993-145005. [CrossRef]

28. Sahin, B.; Yip, T.L.; Tseng, P.H.; Kabak, M.; Soylu, A. An application of a fuzzy TOPSIS multi-criteria decision analysis algorithm for dry bulk carrier selection. Information 2020, 11, 251. [CrossRef]

29. Sahin, B.; Yazir, D.; Soylu, A.; Yip, T.L. Improved fuzzy AHP based game-theoretic model for shipyard selection. Ocean Eng. 2021, 233, 109060. [CrossRef]

30. Yazır, D.; Şahin, B.; Yip, T.L. Selection of new design gas carriers by using fuzzy EVAMIX method. Asian J. Shipp. Logist. 2021, 37, 91-104. [CrossRef]

31. Ramík, J. Fuzzy goals and fuzzy alternatives in goal programming problems. Fuzzy Sets Syst. 2000, 111, 81-86. [CrossRef]

32. Bit, A.; Biswal, M.; Alam, S. An additive fuzzy programming model for multiobjective transportation problem. Fuzzy Sets Syst. 1993, 57, 313-319. [CrossRef]

33. Özkan, M.M. Bulanık Hedef Programlama; Ekin Kitabevi: Bursa, Turkey, 2003.

34. Selim, H.; Ozkarahan, I. A supply chain distribution network design model: An interactive fuzzy goal programming-based solution approach. Int. J. Adv. Manuf. Technol. 2008, 36, 401-418. [CrossRef]

35. Selim, H.; Araz, C.; Ozkarahan, I. Collaborative production-distribution planning in supply chain: A fuzzy goal programming approach. Transp. Res. Part Logist. Transp. Rev. 2008, 44, 396-419. [CrossRef]

36. Guclu, P. Tedarik Zinciri Modelleme Problemine Bulanık Hedef Programlama Yaklaşımı ve bir Uygulama. Ph.D. Thesis, DEÜ Sosyal Bilimleri Enstitüsü, İzmir, Turkey, 2011.

37. Guclu, P.; Ozdemir, A. Bulanık hedef programlama ile tedarik zinciri optimizasyonu: Tekstil sektöründe bir uygulama. Hacet. ÜNiversitesi İKtisadi İDari Bilim. FakÜLtesi Derg. 2015, 33, 77-98.

38. Fallah-Tafti, A.l.; Sahraeian, R.; Tavakkoli-Moghaddam, R.; Moeinipour, M. An interactive possibilistic programming approach for a multi-objective closed-loop supply chain network under uncertainty. Int. J. Syst. Sci. 2014, 45, 283-299. [CrossRef]

39. Torabi, S.; Hassini, E. Multi-site production planning integrating procurement and distribution plans in multi-echelon supply chains: An interactive fuzzy goal programming approach. Int. J. Prod. Res. 2009, 47, 5475-5499. [CrossRef]

40. Panayides, P.M. Maritime logistics and global supply chains: Towards a research agenda. Marit. Econ. Logist. 2006, 8, 3-18. [CrossRef]

41. Song, D.W.; Lee, P.T. Maritime Logistics in the Global Supply Chain; Taylor \& Francis: Oxford, UK, 2009.

42. Song, D.W.; Panayides, P. Maritime Logistics: Contemporary Issues; Emerald Group Publishing: Bingley, UK, 2012.

43. Lisowski, J. Optimization methods in maritime transport and logistics. Pol. Marit. Res. 2018, 25, 30-38. [CrossRef]

44. Kim, K.H.; Hong, B.H. Maritime logistics and applications of information technologies. In Proceedings of the The 40th International Conference on Computers \& Indutrial Engineering, Awaji, Japan, 25-28 July 2010; pp. 1-6. 